\title{
Article \\ Synthesis of Ce/MgO Catalysts for Direct Oxidation of Hibiscus cannabinus Stalks to Vanillin
}

\author{
Nur Akila Syakida Idayu Khairul Anuar ${ }^{1,2}$, Anita Ramli 1,2,*D and Lim Jun Wei 1,2 \\ 1 Fundamental and Applied Sciences Department, Universiti Teknologi PETRONAS, \\ Seri Iskandar 32610, Perak, Malaysia; nur_18003521@utp.edu.my (N.A.S.I.K.A.); \\ junwei.lim@utp.edu.my (L.J.W.) \\ 2 HICOE Centre for Biofuels and Biochemicals Research, Universiti Teknologi PETRONAS, \\ Seri Iskandar 32610, Perak, Malaysia \\ * Correspondence: anita_ramli@utp.edu.my; Tel.: +60-5368-7639
}

Citation: Khairul Anuar, N.A.S.I.; Ramli, A.; Jun Wei, L. Synthesis of $\mathrm{Ce} / \mathrm{MgO}$ Catalysts for Direct Oxidation of Hibiscus cannabinus Stalks to Vanillin. Catalysts 2021, 11, 1449. https://doi.org/10.3390/ catal11121449

Academic Editors: Maria Ricciardi, Raffaele Cucciniello and Roberto Esposito

Received: 21 October 2021

Accepted: 25 November 2021

Published: 28 November 2021

Publisher's Note: MDPI stays neutral with regard to jurisdictional claims in published maps and institutional affiliations.

Copyright: (c) 2021 by the authors. Licensee MDPI, Basel, Switzerland. This article is an open access article distributed under the terms and conditions of the Creative Commons Attribution (CC BY) license (https:// creativecommons.org/licenses/by/ $4.0 /)$.

\begin{abstract}
One possible method of producing vanillin from biomass is through controlled oxidation of lignin. Direct oxidation of kenaf stalks was chosen without having to separate the cellulose and hemicellulose components from the lignocellulosic biomass. This makes the process greener, as well as saving time. In this paper, $\mathrm{Ce} / \mathrm{MgO}$ catalysts were developed for oxidation of kenaf stalks and kenaf lignin under microwave irradiation. The catalysts were characterized for their physicochemical properties using XRD and $\mathrm{N}_{2}$ adsorption-desorption isotherms. The synthesized $\mathrm{MgO}$ showed the presence of diffraction peaks assigned to cubic $\mathrm{MgO}$ while the $30 \mathrm{Ce} / \mathrm{MgO}$ catalysts showed the presence of cubic fluorite of $\mathrm{CeO}_{2} . \mathrm{N}_{2}$ adsorption-desorption isotherms showed that all catalysts possess Type III isotherm according to IUPAC classification, indicating a nonporous structure. All catalysts were tested for direct oxidation of kenaf stalks under $300 \mathrm{~W}$ of microwave irradiation using $\mathrm{H}_{2} \mathrm{O}_{2}$ as the oxidizing agent at $\mathrm{pH} 11.5$ and temperatures between 160 and $180^{\circ} \mathrm{C}$ for $10-30 \mathrm{~min}$ with $5-15 \%$ catalyst loading. The highest vanillin yields of $3.70 \%$ and $2.90 \%$ for extracted lignin and direct biomass oxidation were achieved using $30 \mathrm{Ce} / \mathrm{MgO}-48$. In comparison, $7.80 \%$ and $4.45 \%$ were obtained using $2 \mathrm{~N}$ of $\mathrm{NaOH}$ homogeneous catalyst for extracted lignin and direct biomass, respectively, at $170{ }^{\circ} \mathrm{C}$ for $20 \mathrm{~min}$. The reusability test shows that $30 \mathrm{Ce} / \mathrm{MgO}$ can be used up to three cycles without significant loss in catalytic activity. Other compounds detected were 4-vinylguaiacol, syringol and syringaldehyde.
\end{abstract}

Keywords: direct oxidation; vanillin; microwave heating; $\mathrm{Ce} / \mathrm{MgO}$ catalyst

\section{Introduction}

Vanillin, known as 4-hydroxy-3-methoxybenzaldehyde (Figure 1), is vanilla's primary flavor constituent used as a flavoring and fragrance ingredient in the food and cosmetic industries [1]. The commercial vanillin market is served by three major sources, namely, natural vanilla from vanilla pods, vanillin produced from petrochemical sources and vanillin produced from kraft lignin [2]. The Vanilla planifolia A plant is the best-known natural source of vanillin, which belongs to the orchid family, mainly cultivated in Mexico, Madagascar, Reunion, Java, and Tahiti [3]. However, the production of natural vanillin from vanilla pods covers only $0.2 \%$ of the market requirement and its production cost is very high as it requires manual labor to pollinate the flower [1,4]. Furthermore, the extraction of vanillin from vanilla beans is a long and expensive process, and is inconsistent, and the demand for this universally popular flavoring cannot be satisfied by vanilla beans alone. Nowadays, vanillin produced from petroleum-based intermediates, especially guaiacol, accounts for $85 \%$ of the world supply, while the remaining $15 \%$ is produced from lignin [5]. 




Figure 1. Chemical structure of vanillin [6].

The synthesis of vanillin from renewable sources should result in a greener and more sustainable process. Lignin could be used as a natural precursor from renewable sources to meet the growing demand for natural vanillin as far as the aroma and fragrance fields are concerned. Furthermore, vanillin produced from lignin shows 1.2 times higher aromatic intensity than petroleum-based vanillin [1]. One possible method of producing vanillin through a sustainable process is through the controlled oxidation of lignin from lignocellulosic biomass. Lignin is a three-dimensional amorphous macromolecule and is the most significant renewable material with an aromatic skeleton structure. Lignin's composition and ratio are different for different plants such as hardwood and softwood [7]. Softwoods have a lignin content of $25-35 \%$ dry weight, while the lignin content in hardwoods is $18-25 \%$ [8].

Sales and co-workers [9] reported that the oxidation of lignin to produce vanillin occurs at very alkaline $\mathrm{pH}$ (almost 14$)$ and high temperatures $\left(130^{\circ} \mathrm{C}\right)$ with oxygen pressure higher than 3 bar. They investigated the conversion of alkaline lignin extracted from sugarcane bagasse using batch slurry and continuous fluidized-bed reactors and reported that $0.56 \mathrm{~g}$ of vanillin and $0.5 \mathrm{~g}$ of syringaldehyde were obtained from $30 \mathrm{~g}$ of lignin at $120^{\circ} \mathrm{C}$ after $2 \mathrm{~h}$ [9]. Furthermore, Araujo et al. [10] reported that low-molecular weight lignin derived from softwoods is preferable to than high molecular weight lignin for obtaining a better vanillin yield. They also reported that regardless of the source of lignin, $\mathrm{pH}$ is the essential variable in the reaction, with lower $\mathrm{pH}$ values promoting vanillin degradation, thus reducing the vanillin yield.

The oxidizing agent used for the oxidation reaction also significantly influences the yield of vanillin produced, as observed by Alireza et al. [6], where $4.2 \%$ and $1.2 \%$ of vanillin yield were reported from oxidation of industrial lignin using molecular oxygen and alkaline nitrobenzene, respectively. Furthermore, Valery et al. [11] reported a vanillin yield of $18.6 \%$ when lignin extracted from powdered pine wood using standard alcohol-toluene as a solvent was oxidized using copper oxide ( $\mathrm{CuO}$ ) catalyst. On the other hand, Chen et al. [12] reported that a $4.2 \%$ vanillin yield was achieved from the direct oxidation of Japanese cedar wood particles in $\mathrm{CuO}$ as the catalyst and $\mathrm{H}_{2} \mathrm{O}_{2}$ solution as an oxidizing agent under microwave irradiation at $200{ }^{\circ} \mathrm{C}$ for $20 \mathrm{~min}$.

Chaudhary and Dhepe [13] reported that solid acids, homogeneous acids, ionic liquid, supercritical fluids yield low molecular weight aromatic products. However, most of these methods were linked to a few problems such as high temperatures $\left(\geq 250{ }^{\circ} \mathrm{C}\right)$ or pressures $(>3 \mathrm{MPa}$ ) or both for operation parameters. Alkaline oxidation of lignin is considered the only approach that yields large amounts of single monomeric aldehydes that are the predominant products in the presence of base catalysts. However, the conversion of lignin to vanillin requires a very high $\mathrm{pH}$ and this is usually achieved by using $\mathrm{NaOH}$ as the solvent, resulting in problems of corrosion and pollution. A study carried out by Long et al. [14] reported a $13.2 \%$ yield phenolic monomers, including vanillin obtained during lignin depolymerization using $\mathrm{MgO}$ solid base catalyst, while Biswas et al. [15] stated that the properties of the high base of $\mathrm{CaO} / \mathrm{CeO}_{2}$ catalysts enhanced the cleavage of $\beta-\mathrm{O}-4$ in the lignin structure, thus increasing the reaction's selectivity. Base catalysts are very interesting 
for alkaline oxidation of lignin; therefore, alkaline solid catalysts based on $\mathrm{MgO}$ were developed. The basicity of $\mathrm{MgO}$ was modified using Ce to increase its basicity properties.

Kenaf (Hibiscus cannabinus) is a commodity crop with a high potential to produce renewable vanillin since it contains $13-15 \%$ lignin [16]. In this paper, we report the vanillin production from direct oxidation of kenaf stalks and kenaf lignin using $30 \mathrm{Ce} / \mathrm{MgO}$ under microwave irradiation.

\section{Result}

\subsection{Catalyst Characterization}

Figure 2 shows the $\mathrm{X}$-ray diffractograms of $\mathrm{MgO}$ synthesized using sol-gel and hydrothermal methods (more details are available in Figure S1). The presence of diffraction peaks at $2 \theta=29.33,36.90,42.85,62.13,74.65$ and $78.40^{\circ}$ indicate the formation of cubic phase of MgO [10] which could be assigned to (100), (111), (200), (220), (311) and (222) planes, respectively [17,18]. Based on ICDD: 00-04500946, the diffraction peak of MgO exhibits a crystalline periclase of magnesium oxide with a cubic crystal system, as reported by Araujo et al. [10]. The result is similar to that reported by Bing et al. [19], where they observed diffraction peaks at $2 \theta$ value of $36.94,43.01,62.21,74.62,78.63^{\circ}$, which can be indexed to the standard diffraction spectra of $\mathrm{MgO}$ powder. However, Araujo et al. [10] and Bing et al. [19] did not report the presence of a $\mathrm{Mg}(100)$ peak at a $2 \theta$ value of 29.33. On the other hand, Xiangcun et al. [20] showed that there was the formation of impurity of $\mathrm{Mg}(\mathrm{OH})_{2}$ at $2 \theta$ value around $30^{\circ}$ in the XRD pattern, which could be due to high hydration properties of $\mathrm{MgO}$ materials. In general, the intensity of the peaks was higher when the $\mathrm{MgO}$ was synthesized using the hydrothermal method (MgO-18, MgO-36 and $\mathrm{MgO}-48$ ) compared to $\mathrm{MgO}$ synthesized using the sol-gel method (MgO-SG). The hydrothermal method can increase crystallite size with good structure; hence the crystal quality is improved [21] compared to the sol-gel method, which results in a higher specific surface area [22].



Figure 2. X-ray diffraction patterns of MgO synthesized using sol-gel and hydrothermal methods at $\mathrm{pH} 12$.

From the result, $\mathrm{MgO}-36$ showed the highest peak intensity at the plane (200), followed by $\mathrm{MgO}-18$ and $\mathrm{MgO}-48$. Increasing intensity peaks from 18 hours to $48 \mathrm{~h}$ synthesized duration can be related to Ahmedet al.'s study [23], which suggested that the catalyst shows the high structural ordering of mesopores in the material due to stronger intensity of peaks in the XRD spectrum. However, further extension duration to $48 \mathrm{~h}$ synthesis resulted in 
decreased intensity peaks at the plane (200), which could be due to the structural ordering decreases in the material as the interplanar spacing increases, as reported by Ahmed [23].

When the synthesized $\mathrm{MgO}$ was impregnated with $30 \% \mathrm{Ce}$, the formation of new peaks with low intensities were observed at $2 \theta=28.51,33.32,47.60,56.35$ and $78.71^{\circ}$ (Figure 3 and Figure S2) in all $30 \mathrm{Ce} / \mathrm{MgO}$ catalysts, which could be assigned to Ce (111), $\mathrm{Ce}$ (200), Ce (220), Ce (311) and Ce (331) planes, respectively, indicating the formation of cubic fluorite structure of $\mathrm{CeO}_{2}$ as referenced from ICSD: 28709 [24,25]. Furthermore, the intensities of all $\mathrm{MgO}$ peaks is reduced while the $\mathrm{Mg}(200)$ and (220) peaks shifted to slightly higher $2 \theta$ value of 43.17 and $62.94^{\circ}$, respectively, with lower intensities. The results are in agreement with research reported by Setoudeh et al. [26] that shows diffraction peaks of $\mathrm{MgO}$ would slightly shift to higher angles due to the diffusion of $\mathrm{Ni}^{2+}$ ions into the $\mathrm{MgO}$ lattice, while the diffusion of $\mathrm{Mg}^{2+}$ into $\mathrm{Ni}^{2+}$ lattice would result in the peaks to slightly lower angles. These phenomena are attributed to the presence of Ce diffused into the $\mathrm{MgO}$ lattice [27].



Figure 3. X-ray diffraction patterns of $\mathrm{MgO}$-supported $\mathrm{CeO}_{2}$ catalysts.

Table 1 shows the estimated crystallite size of the synthesized $\mathrm{MgO}$ and $\mathrm{CeO}_{2}$, determined from the diffraction peaks for (200) and (111), respectively. The calculation of the crystallite size is based on the highest intensity peak for both $\mathrm{MgO}$ and $\mathrm{CeO}_{2}$. The result showed decreased crystallite size as the hydrothermal duration process increased from 18 
to $36 \mathrm{~h}$. However, the crystallite size increases as the duration process are prolonged to $48 \mathrm{~h}$ for $\mathrm{MgO}$ catalysts, while MgO-36 shows a smaller crystallite size than MgO-18 and $\mathrm{MgO}-48$. Soo Min et al. [28] observed that XRD peaks become sharper as the duration for hydrothermal treatment was increased as prolonged duration at hydrothermal temperature allows the crystals to grow more extensive during the hydrothermal process.

Table 1. Crystallite size of $\mathrm{MgO}$ and $\mathrm{MgO}-$ supported Ce catalysts.

\begin{tabular}{ccc}
\hline & \multicolumn{2}{c}{ Crystallite Size (nm) } \\
\cline { 2 - 3 } Catalyst & Mg (200) & Ce (111) \\
\hline MgO-18 & 36.5 & - \\
MgO-36 & 29.9 & - \\
MgO-48 & 48.4 & - \\
MgO-SG & 32.8 & - \\
30Ce/MgO-18 & 43.9 & 3.9 \\
30Ce/MgO-36 & 50.7 & 4 \\
30Ce/MgO-48 & 40.0 & 7.4 \\
30-Ce/MgO-SG & 45.3 & 7.1 \\
\hline
\end{tabular}

The observation of the crystallite size trend for MgO-supported Ce catalysts shows a different pattern than for the $\mathrm{MgO}$ catalyst. From Table 1 , it is clear that the $30 \mathrm{Ce} / \mathrm{MgO}$ catalyst displays an increasing pattern, as hydrothermal duration increases from $18 \mathrm{~h}$ to $36 \mathrm{~h}$. However, a contradiction trend in crystallite size was observed as the crystallization period was further increased to 48 for $30 \mathrm{Ce} / \mathrm{MgO}-48$ compared to $30 \mathrm{Ce} / \mathrm{MgO}-18$ and $30 \mathrm{Ce} / \mathrm{MgO}-36$ catalysts. $30 \mathrm{Ce} / \mathrm{MgO}-48$ possesses a smaller crystallite size, as the order of increasing crystallite size is $30 \mathrm{Ce} / \mathrm{MgO}-36>30 \mathrm{Ce} / \mathrm{MgO}-\mathrm{SG}>30 \mathrm{Ce} / \mathrm{MgO}-18>30 \mathrm{Ce} / \mathrm{MgO}-$ 48. Crystallite size at $\mathrm{Ce}(111)$ plane shows a clear increasing pattern as synthesis duration increases. It could be caused by a lower state of dispersion of $\mathrm{Ce}$ at the site into the support surface, due to the agglomeration of impregnated metal into $\mathrm{MgO}$ pores/channel or surface as synthesized duration increases from $18 \mathrm{~h}$ to $48 \mathrm{~h}$ [29].

Figure 4 shows the $\mathrm{N}_{2}$ adsorption-desorption isotherms of $\mathrm{MgO}$-supported Ce catalysts, where all samples show a combination of Type II isotherms with a knee shape isotherm at a very low relative pressure $\left(\mathrm{p} / \mathrm{p}_{\mathrm{o}}\right)$ and Type III isotherms at higher $\mathrm{p} / \mathrm{p}_{\mathrm{o}}$ according to IUPAC classification, a characteristic of non-porous materials [30,31]. Moreover, the isotherm destination turns upward at high relative pressure, which could be attributed to the voids between the particles [32]. Li et al. [33] stated that $\mathrm{MgO}$ exhibits a typical typeIII isotherm-the $\mathrm{N}_{2}$ adsorption-desorption isotherm, which is a typical characteristic of a porous structure with a significant $\mathrm{H} 3$ hysteresis loop. They also reported that observation at medium relative pressure $(\mathrm{p} / \mathrm{po})$ range of $0.5-1.0$ confirmed the presence of substantial mesopores in the $\mathrm{MgO}$ nanoparticles [33].

Table 2 shows the textural properties of the $\mathrm{MgO}$ and $\mathrm{MgO}$-supported Ce catalysts where the surface area, pore volume and average pore size of $\mathrm{MgO}$ synthesized using the hydrothermal method increased when the crystallization period was increased from 18 to $36 \mathrm{~h}$. However, when the crystallization period was further increased to $48 \mathrm{~h}$, the surface area, pore volume and average pore size of the $\mathrm{MgO}$ decreased as the crystallite size of the $\mathrm{MgO}$ crystals that were formed also showed increases. The surface area and crystallite size of all catalysts showed a clear contradiction trend to each other, which agrees with the findings stated by Chowdhury et al. [33] and Li et al. [24]. Both studies reported that a bigger total surface area of the materials would result in larger interparticle porosity or voids between particles, thus reducing the crystallite size of the materials. As can be seen, $\mathrm{MgO}-36$ showed the highest surface area $\left(34.6 \mathrm{~m}^{2} / \mathrm{g}\right)$ with the smallest crystallite size $(29.9 \mathrm{~nm}$ ) among other $\mathrm{MgO}$ catalysts, while $\mathrm{MgO}-48$ showed the smallest surface area $\left(13.5 \mathrm{~m}^{2} / \mathrm{g}\right)$ with the biggest crystallite size $(48.4 \mathrm{~nm})$. The result obtained was also in agreement with the study carried out by Sui et al. [34] that showed $\mathrm{CeO}_{2}$ support, and the $\mathrm{Co} / \mathrm{CeO}_{2}$ catalyst exhibited a smaller particle size correlated with a higher specific 
surface area. For $30 \mathrm{Ce} / \mathrm{MgO}$ catalysts, $30 \mathrm{Ce} / \mathrm{MgO}-48$ also showed the highest surface area $\left(29.3 \mathrm{~m}^{2} / \mathrm{g}\right)$ compared to other $30 \mathrm{Ce} / \mathrm{MgO}$ catalysts. Among the $30 \mathrm{Ce} / \mathrm{MgO}$ catalysts, the surface area increases in an order of $30 \mathrm{Ce} / \mathrm{MgO}-48>30 \mathrm{Ce} / \mathrm{MgO}-\mathrm{SG}>30 \mathrm{Ce} / \mathrm{MgO}-18>$ $30 \mathrm{Ce} / \mathrm{MgO}-36$.

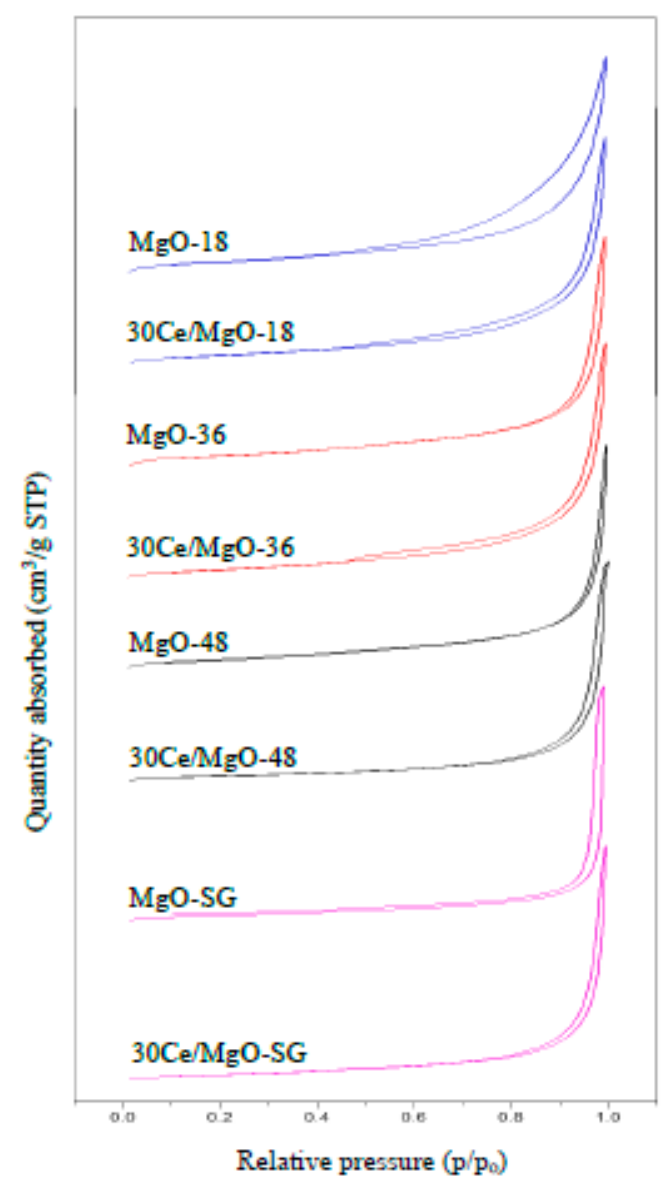

Figure $4 . \mathrm{N}_{2}$ adsorption-desorption isotherms of the catalyst.

Table 2. Textural properties of $\mathrm{MgO}$ and $30 \mathrm{Ce} / \mathrm{MgO}$ catalyst.

\begin{tabular}{|c|c|c|c|c|}
\hline Catalyst & $\begin{array}{l}\text { BET Surface } \\
\text { Area }\left(\mathrm{m}^{2} / \mathrm{g}\right)\end{array}$ & $\begin{array}{l}\text { Pore Volume } \\
\qquad\left(\mathrm{cm}^{3} / \mathrm{g}\right)\end{array}$ & $\begin{array}{l}\text { Average Pore } \\
\text { Size (nm) }\end{array}$ & $\begin{array}{c}\text { Crystallite Size } \\
\text { (nm) }\end{array}$ \\
\hline $\mathrm{MgO}-18$ & 28.4 & 0.193 & 21.7 & 36.5 \\
\hline $\mathrm{MgO}-36$ & 34.6 & 0.285 & 36.4 & 29.9 \\
\hline $\mathrm{MgO}-48$ & 13.4 & 0.076 & 14.4 & 48.4 \\
\hline MgO-SG & 27.3 & 0.146 & 20.4 & 32.8 \\
\hline $30 \mathrm{Ce} / \mathrm{MgO}-18$ & 27.5 & 0.165 & 18.8 & 43.9 \\
\hline $30 \mathrm{Ce} / \mathrm{MgO}-36$ & 25.9 & 0.158 & 18.2 & 50.7 \\
\hline $30 \mathrm{Ce} / \mathrm{MgO}-48$ & 29.3 & 0.293 & 32.3 & 40.0 \\
\hline 30Ce/MgO-SG & 28.4 & 0.247 & 30.2 & 45.3 \\
\hline
\end{tabular}

\subsection{Lignin Extraction}

Mohamad Aini et al. [35] reported that lignin content in kenaf is $19.2-21.2 \%$. The lignin extracted from kenaf in this work is $23.5 \%$ compared to $20.8 \%$ reported earlier by Mohamad Aini et al. [35] for lignin extraction from kraft lignin of kenaf. On the other hand, Yang et al. [36] reported that $16.7 \%$ lignin was extracted from kenaf bast using the acid hydrolysis method. Figure 5 shows the infrared spectra of the extracted lignin, while the interpretation is tabulated in Table 3 and is compared with that reported in the literature. 


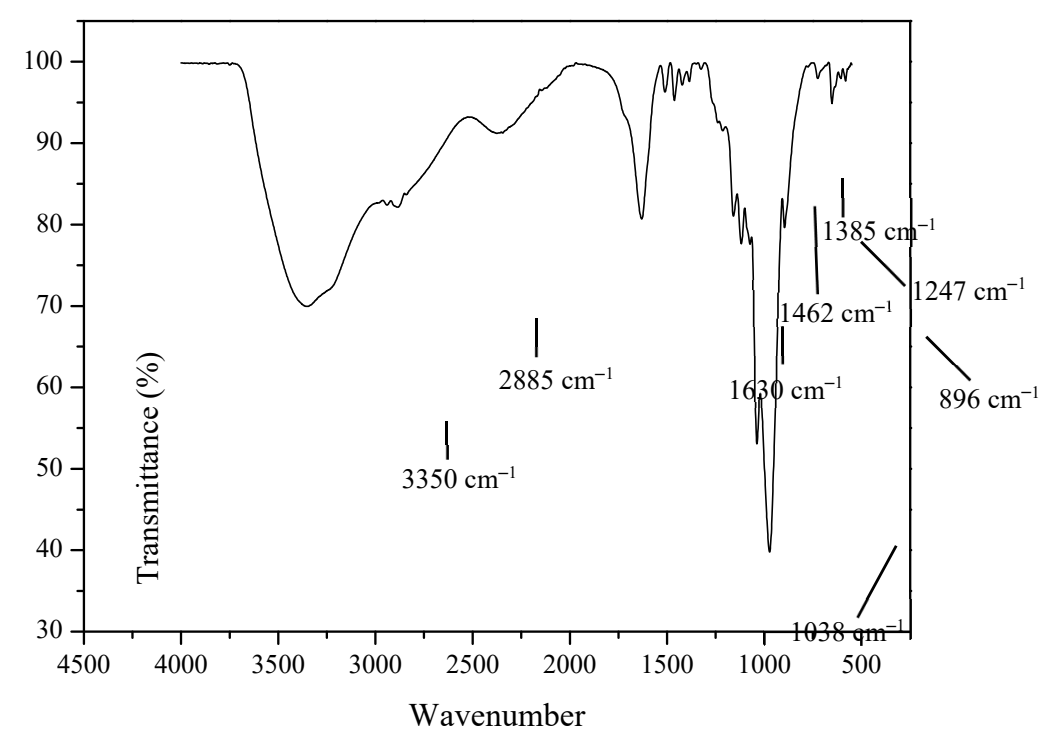

Figure 5. FTIR spectra of dried kenaf stalk's lignin.

According to Table 3, the broad peak at $3350 \mathrm{~cm}^{-1}$ is attributed to the stretching vibration of $\mathrm{O}-\mathrm{H}$ bonds [37], and the band at $2886 \mathrm{~cm}^{-1}$ is attributable to the C-H stretching vibration in the methyl and methylene groups [38]. The $\mathrm{C}-\mathrm{H}$ bending vibration in the methyl groups can be allocated to the band at $1462 \mathrm{~cm}^{-1}$ [39]. The band 1650-1590 was due to $\mathrm{C}=\mathrm{C}$ aromatic vibrations exhibiting the presence of lignin. The bands for $\mathrm{C}=\mathrm{O}$ stretching vibration in the syringyl propane unit $(\mathrm{S})$ and the guaiacyl propane unit $(\mathrm{G})$ are at $1385 \mathrm{~cm}^{-1}$ and $1247 \mathrm{~cm}^{-1}$, respectively [40]. The band at $1037 \mathrm{~cm}^{-1}$ can be assigned to the $\mathrm{C}=\mathrm{O}$ deformation in secondary and primary alcohol or aliphatic esters [41]. An absorption band at $897 \mathrm{~cm}^{-1}$ was assigned to $\mathrm{C}-\mathrm{O}-\mathrm{C}$ stretching at the $\beta-(1,4)-$ glycosidic linkage in cellulose [42].

Table 3. Functional group and frequency of FTIR.

\begin{tabular}{|c|c|c|c|}
\hline \multicolumn{3}{|c|}{ IR Band $\left(\mathrm{cm}^{-1}\right)$} & \multirow{2}{*}{ Assignment } \\
\hline Literature Data & [ref] & Data Obtained & \\
\hline $3500-3100$ & [35] & 3350 & Stretching vibration of $\mathrm{O}-\mathrm{H}$ bonds \\
\hline $2900-2800$ & {$[38]$} & 2886 & $\begin{array}{l}\mathrm{C}-\mathrm{H} \text { stretching vibration in the methyl and } \\
\text { methylene groups }\end{array}$ \\
\hline $1650-1590$ & {$[40]$} & 1630 & $\mathrm{C}=\mathrm{C}$ aromatic vibrations \\
\hline $1464-1424$ & [39] & 1462 & $\mathrm{C}-\mathrm{H}$ bending vibration in the methyl groups \\
\hline $1272-1265$ & {$[40]$} & 1247 & $\begin{array}{c}\mathrm{C}=\mathrm{O} \text { stretching vibration in guaiacyl propane } \\
\text { units }(\mathrm{G})\end{array}$ \\
\hline $1340-1330$ & {$[40]$} & 1385 & $\begin{array}{c}\mathrm{C}=\mathrm{O} \text { stretching vibration in syringyl propane } \\
\text { units }(\mathrm{S})\end{array}$ \\
\hline 1130-1035 & {$[41]$} & 1038 & $\begin{array}{c}\mathrm{C}=\mathrm{O} \text { deformation in secondary and primary } \\
\text { alcohol or aliphaticesters }\end{array}$ \\
\hline $897-889$ & {$[42]$} & 896 & $\begin{array}{c}\mathrm{C}-\mathrm{O}-\mathrm{C} \text { stretching at the } \beta-(1,4) \text {-glycosidic } \\
\text { linkage in cellulose }\end{array}$ \\
\hline
\end{tabular}

\subsection{Catalyst Testing}

Figure 6 shows the HPLC chromatogram of vanillin standard, where it shows that the retention time of vanillin is $5.730 \mathrm{~min}$. Based on this chromatogram, five different concentrations of standard vanillin were prepared for the calibration curve to allow for the quantitative determination of the vanillin produced from direct oxidation of kenaf stalks. 


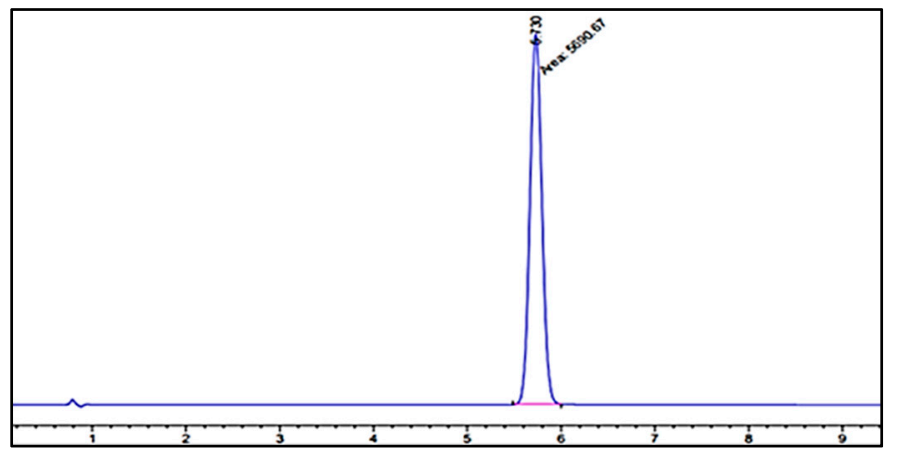

Figure 6. HPLC chromatogram of vanillin standard.

Figure 7 shows the calibration curve of vanillin standard at five different concentrations $\left(1.25 \times 10^{-4}, 6.25 \times 10^{-5}, 3.125 \times 10^{-5}, 1.56 \times 10^{-5}\right.$ and $\left.7.81 \times 10^{-6}\right)$ using HPLC. The curve was plotted to measure the peak area attained from the injected aliquot of standard vanillin solution with known concentration. The calibrated curve will be used to determine the vanillin yield quantitatively. The correlation coefficient, $\mathrm{R}^{2}$ of the best-fit line displayed at 0.9995, indicates high accuracy.



Figure 7. Calibration curve of the vanillin standard at five different concentrations.

When the catalysts were tested in the direct oxidation of kenaf stalks, the liquid produced from oxidation in the presence of $30 \mathrm{Ce} / \mathrm{MgO}-36$ shows the presence of vanillin at the retention time of $5.73 \mathrm{~min}$ (Figure 8). However, the chromatogram also shows the presence of three other compounds at the retention time of $1.38,3.98$ and $7.18 \mathrm{~min}$. The other compounds could be 4-vinylguaiacol, syringol and syringaldehyde, respectively.

Vanillin was detected in the liquid produced from direct oxidation of kenaf stalks in all $\mathrm{MgO}$-supported Ce catalysts. In contrast, no vanillin was detected when $\mathrm{MgO}$ was used as the catalyst, which indicates that $\mathrm{Ce}$ is the active component responsible for the formation of vanillin. Using the linear equation derived from the calibration curve (Figure 7), the vanillin produced from direct oxidation of kenaf stalks at $180{ }^{\circ} \mathrm{C}$ and ambient pressure can be calculated. Our earlier work on converting lignin derived from pineapple leaves shows a vanillin yield of $6 \%$ at $170{ }^{\circ} \mathrm{C}$ and pressure of 15 bars by using compressed air as an oxidizing agent [43]. 




Figure 8. HPLC chromatogram of derived vanillin.

Figure 9 shows the effect of reaction time on vanillin yield. There are no significant differences in vanillin yield for all catalysts at reaction duration of 10 and $30 \mathrm{~min}$. At the same time, there is an increasing trend for catalyst $30 \mathrm{Ce} / \mathrm{MgO}-48$ compared to other catalysts at a 20 -minute reaction duration. The $30 \mathrm{Ce} / \mathrm{MgO}-48$ catalyst showed the highest vanillin yield of $0.684 \%$ when the reaction was performed for $20 \mathrm{~min}$ at $180{ }^{\circ} \mathrm{C}$, while $30 \mathrm{Ce} / \mathrm{MgO}-18$, $30 \mathrm{Ce} / \mathrm{MgO}-36$ and $30 \mathrm{Ce} / \mathrm{MgO}-\mathrm{SG}$ gave a vanillin yield of $0.152,0.217$ and $0.202 \%$, respectively. This is considered substantial since the vanillin is produced directly from kenaf stalks without separating the lignin from the cellulose and hemicellulose components.

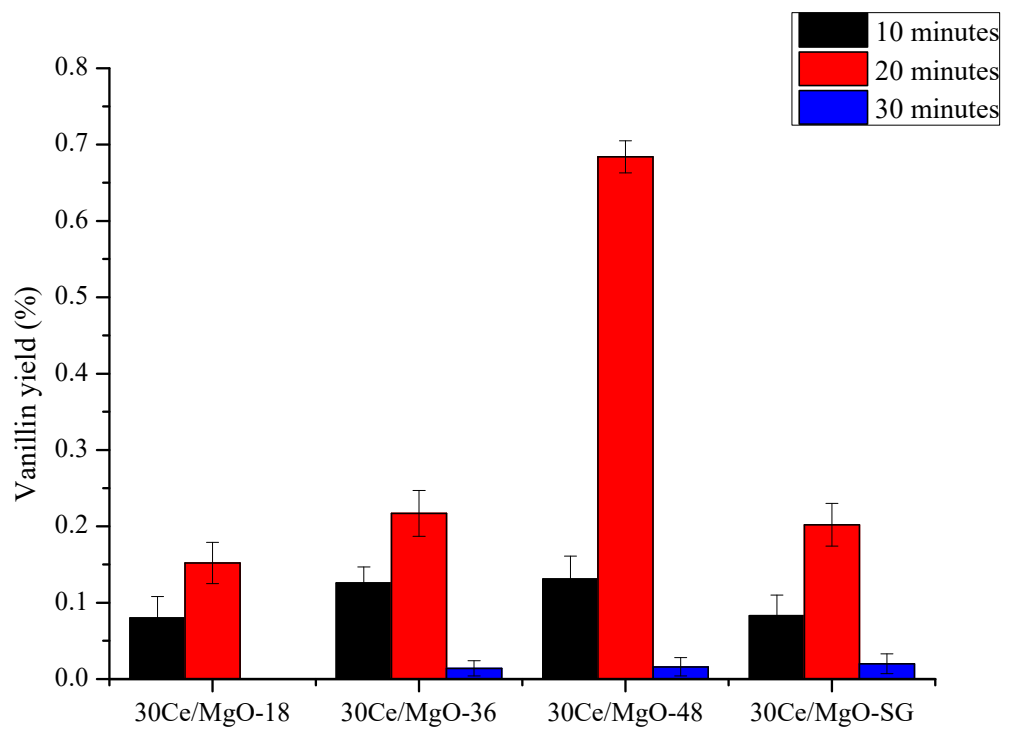

Figure 9. Reaction condition: $2 \mathrm{~g}$ of dried kenaf stalks, $20 \mathrm{~mL}$ of $0.01 \mathrm{~N} \mathrm{NaOH}$ solution, $10 \mathrm{wt} . \%$ of catalyst, $1 \mathrm{~mL}$ of $\mathrm{H}_{2} \mathrm{O}_{2}$ at $180^{\circ} \mathrm{C}$.

Furthermore, the reaction was performed at $\mathrm{pH} 11.5$, which is lower than $\mathrm{pH} 12-14$ as reported by other researchers $[1,10]$. Direct production of vanillin has also been achieved by Chen et al. [12]. Japanese cedar wood was used as a biomass source that gives $5 \%$ vanillin yield. The $\mathrm{CuO}$ catalyst combined with $\mathrm{H}_{2} \mathrm{O}_{2}$ solution as an oxidant showed the best yield for $20 \mathrm{~min}$ under $180^{\circ} \mathrm{C}$. From this result, $20 \mathrm{~min}$ was chosen as the optimum reaction time. Das et al. [44] stated that further extension duration might lead to low product yield due to repolymerization of depolymerized lignin or over-oxidized products that form during the time while the reaction occurs. The research properties were continued to determine the effect of reaction temperature on the vanillin yield.

There was no vanillin produced using MgO catalyst; however, by using ceria loading, the presence of vanillin was detected. Nolan et al. [45] reported that ceria could be an 
active catalyst due to its high oxygen storage capacity, which can absorb/release oxygen under oxidizing/reducing conditions. It is related to the comparatively facile formation of $\mathrm{O}$ vacancies in $\mathrm{CeO}_{2}$ [46]. Several studies have investigated and confirmed the presence of peroxide species on $\mathrm{CeO}_{2}$ surfaces, but these have been solely related to adsorbed molecular oxygen [47]. Oxidation reactions continuously occur because oxidized surfaces of ceria are being provided by peroxide, which acts as an oxidant in the reaction. The low mass transfer and low concentration rate of $\mathrm{O}_{2}$ during the reaction are also being provided by $\mathrm{H}_{2} \mathrm{O}_{2}$ [44].

Figure 10 shows the effect of reaction temperature on vanillin yield using all the $\mathrm{MgO}$-supported Ce catalysts. Vanillin yields increase with increasing reaction temperature from 160 to $170{ }^{\circ} \mathrm{C}$ using all catalysts. However, the vanillin yield decreased when the temperature was further increased to $180{ }^{\circ} \mathrm{C}$ regardless of the catalyst used, which could be attributed to the degradation of vanillin at high temperatures, as reported by Chen et al. [12]. Based on Yuting et al. [37], prolonging the reaction time did not improve the vanillin yield, which could be caused by low selectivity due to tandem reaction. According to Tarabanko et al. [48], increasing the temperature of aspen wood oxidation to more than $160{ }^{\circ} \mathrm{C}$ can give a higher yield of vanillin and syringaldehyde, while another study showed a high aromatic aldehyde yield in aspen wood oxidation when the temperature was raised from $110^{\circ} \mathrm{C}$ to $160^{\circ} \mathrm{C}[48,49]$.

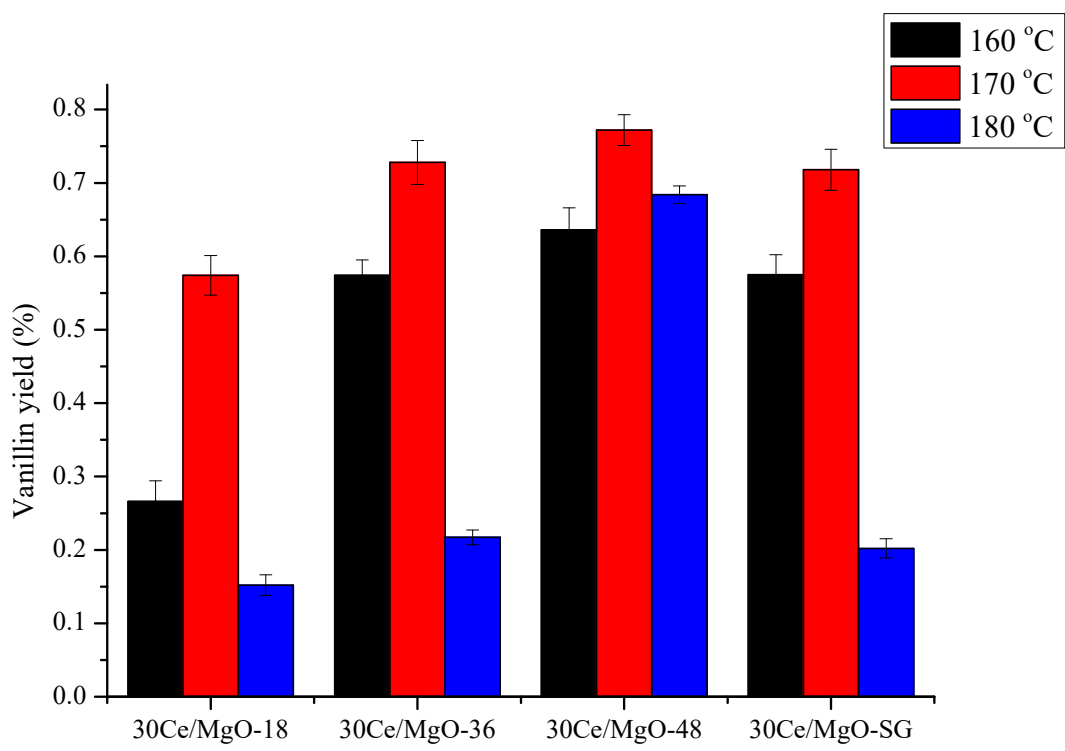

Figure 10. Reaction condition: $2 \mathrm{~g}$ of dried kenaf stalks, $20 \mathrm{~mL}$ of $0.01 \mathrm{~N} \mathrm{NaOH}$ solution, $10 \mathrm{wt}$. $\%$ of catalyst, $1 \mathrm{~mL}$ of $\mathrm{H}_{2} \mathrm{O}_{2}$ at $20 \mathrm{~min}$.

Figure 10 shows that $170{ }^{\circ} \mathrm{C}$ reaction temperature with a 20-minute reaction time presents the high vanillin yield, which was $0.772 \%$ in the presence of $30-\mathrm{Ce} / \mathrm{MgO}-48$ catalyst and followed by $0.728,0.718,0.716 \%$ for $30 \mathrm{Ce} / \mathrm{MgO}-36,30 \mathrm{Ce} / \mathrm{MgO}-\mathrm{SG}, 30 \mathrm{Ce} / \mathrm{MgO}-18$ catalysts, respectively.

Based on the vanillin yield obtained in Figures 9 and 10, 30Ce/MgO-48 shows the higher vanillin yield for reaction time and temperature. Hence, 30Ce/MgO-48 was chosen as the best catalyst for further optimization on catalyst loading with a fixed amount of biomass. Figure 11 shows the vanillin yield obtained on the different amounts $(5,10$ and 15 wt. $\%$ ) of $30 \mathrm{Ce} / \mathrm{MgO}-48$ catalyst loading synthesized with $2 \mathrm{~g}$ of kenaf dried stalks for $20 \mathrm{~min}$ at $170{ }^{\circ} \mathrm{C}$ under microwave heating. The result shows the increased number of yields with the increased amount of catalyst loading with vanillin yield of $0.141 \%$ (5 wt. $\%$ ), $0.772 \%$ (10 wt. $\%$ ) and 1.37\% (15 wt. \%). These were due to the higher total contact frequency of catalysts with lignin, as reported by Chen et al. [12]. In addition, higher catalyst dosage indicates a much more catalytic active center resulting in higher catalytic performance [50]. 
This result is also in agreement with the research carried out by Prado et al. [51], which stated that increasing catalyst loading from $1 \%$ to $20 \%$ preceded to greater vanillin yield from 0.015 to $0.22 \%$. It is also speculated that increases in catalyst loading resulted in more active sites available to break down lignin into aromatic aldehyde products.



Figure 11. Reaction condition: $2 \mathrm{~g}$ of dried kenaf stalks, $20 \mathrm{~mL}$ of $0.01 \mathrm{~N} \mathrm{NaOH}$ solution, $1 \mathrm{~mL}$ of $\mathrm{H}_{2} \mathrm{O}_{2}$ at $20 \mathrm{~min}$ for $170{ }^{\circ} \mathrm{C}$.

Figure 12 shows vanillin production from extracted lignin and biomass synthesized using $15 \mathrm{wt} . \%$ of heterogeneous and homogeneous catalyst for $20 \mathrm{~min}$ at $170{ }^{\circ} \mathrm{C}$ under microwave heating. The optimum operating conditions for a time, temperature and catalyst loading were chosen to synthesize the extracted lignin and direct biomass for vanillin production in the presence of heterogeneous $(30 \mathrm{Ce} / \mathrm{MgO}-48)$ and homogeneous $(\mathrm{NaOH})$ catalysts. This study was performed to compare their catalytic performance and obtained yield on vanillin production. The vanillin yield obtained in the presence of $30 \mathrm{CeMgO}-48$ as heterogeneous catalysts were $3.70 \%$ and $2.90 \%$ for oxidations of extracted lignin and the direct oxidation of biomass, respectively. On the other hand, $7.80 \%$ and $4.45 \%$ were obtained in the presence of $2 \mathrm{~N} \mathrm{NaOH}$ as a homogeneous catalyst for oxidations of extracted lignin and direct biomass, respectively.

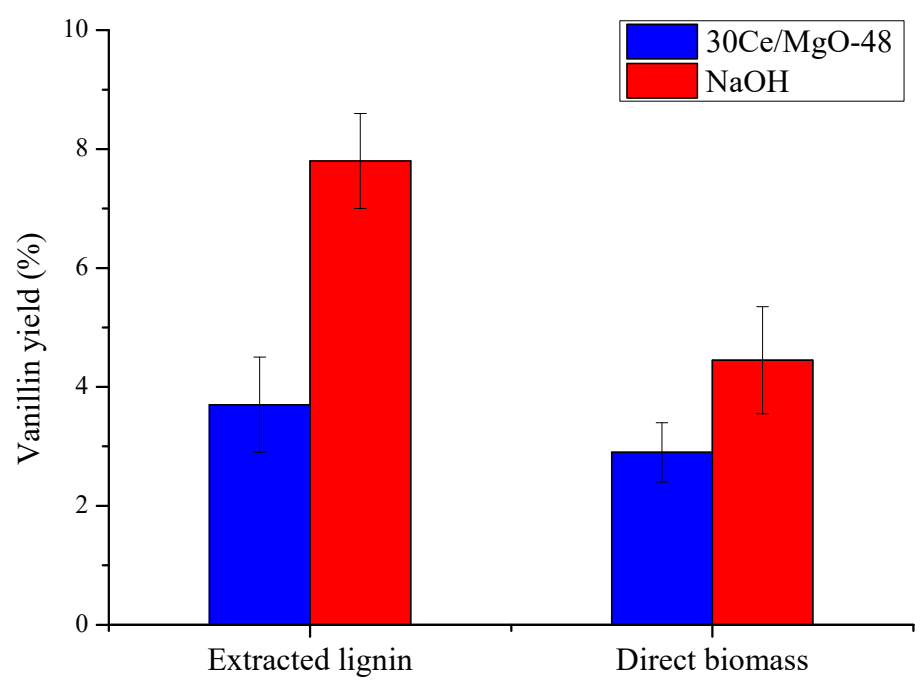

Figure 12. Reaction condition: $2 \mathrm{~g}$ of dried kenaf stalks and $1.06 \mathrm{~g}$ of extracted lignin, $20 \mathrm{~mL}$ of $0.01 \mathrm{~N}$ $\mathrm{NaOH}$ solution, $15 \mathrm{wt} . \%$ of catalyst, $1 \mathrm{~mL}$ of $\mathrm{H}_{2} \mathrm{O}_{2}$ at $20 \mathrm{~min}$ for $170{ }^{\circ} \mathrm{C}$. 
Extracted lignin obtained a higher vanillin yield than direct biomass because of the isolation of lignin as an active compound for conversion to vanillin. The vanillin production is caused by the breaking down of aryl ether linkages in $\beta-\mathrm{O}-4$ bonds and $\mathrm{C}_{\alpha}-\mathrm{C}_{\beta}$ cleavage between lignin structures through the oxidation process. Compared to biomass, the oxidation process directly to biomass without separating lignin with cellulose and hemicellulose was the cause of lower vanillin yield. According to Lu et al. [52], more than $50 \%$ of aryl ether bonds ( $\beta-\mathrm{O}-4)$ are contained in the lignin structure. Furthermore, the $(\beta-\mathrm{O}-4)$ bonds are a stable linkage $\left(52-75 \mathrm{kcal} \mathrm{mol}^{-1}\right)$ and require high energy for the cleavage process to occur [53]. In this regard, the use of catalysts is vital for the efficient and selective cleavage of $(\beta-\mathrm{O}-4)$ bonds because of the unique characteristics of catalysts that render them able to control the activation routes of cleavage [54]. Cleavage ( $\beta-\mathrm{O}-4)$ bonds in the lignin structure from direct biomass are challenging because the lignin structure is not separated from cellulose and hemicellulose components.

As reported by previous studies, the use of supported or unsupported metal catalysts such as Pd [52], Ce [55], V [56], $\mathrm{Ni}$ [52], $\mathrm{Cu}$ [57] and $\mathrm{Ru}$ [58] as heterogeneous catalysts was successful in producing vanillin with high selectivity and conversion percentage. However, there are limitations during the reaction process where the reaction cannot proceed for a new turn when the lignin fragment is saturated on the catalyst's surface. On the other hand, the homogeneous catalyst is counted as flexible a catalyst that allows them to freely contact the $\mathrm{C}_{\mathrm{Ar}}-\mathrm{O}$ bonds without high steric limitation, since the reaction occurs solely in a liquid phase. This condition results in a reduction in mass transfer limitations [59], which is one of the reasons for the high production yield of vanillin in the presence of homogeneous catalysts compared to heterogeneous catalysts. Moreover, $\mathrm{NaOH}$ was used as a homogeneous catalyst during the oxidation reaction. A study reported by Lopes et al. [54] stated that using Ionic Liquids (ILs) as a green framework, ground-breaking homogeneous catalysis for lignin depolymerization had been developed and it can act as a solvent and catalyst at the same time. They also stated that the cleavage of lignin ether bonds was promoted by acidic ILs approaches.

The reusability of the $30 \mathrm{Ce} / \mathrm{MgO}-48$ catalyst was determined by the repeated use of the catalyst for the direct oxidation of Kenaf stalks to vanillin production three times with the new reactants and optimized reaction conditions. After the first use, the recovered catalyst was washed with ethanol to remove the organic deposits such as unreacted biomass and derived biomass product, then dried at $100{ }^{\circ} \mathrm{C}$ for $12 \mathrm{~h}$. Figure 13 shows that the $30 \mathrm{Ce} / \mathrm{MgO}-48$ catalyst is chemically stable and can be repeated for a third time with a slightly significant loss in activity compared to vanillin's yield in the first use of catalyst. There are $0.5 \%$ yield differences between the first and second cycle with $2.90 \%$ and $2.54 \%$, while there are no significant in yield obtained for the third cycle with $2.52 \%$ vanillin. The slight decrease in vanillin production for the second cycle may be attributed to the saturated surface of catalyst by side product of biomass, including a major lignin-like oligomers product from vanillin oxidative polymerization [60,61]. 


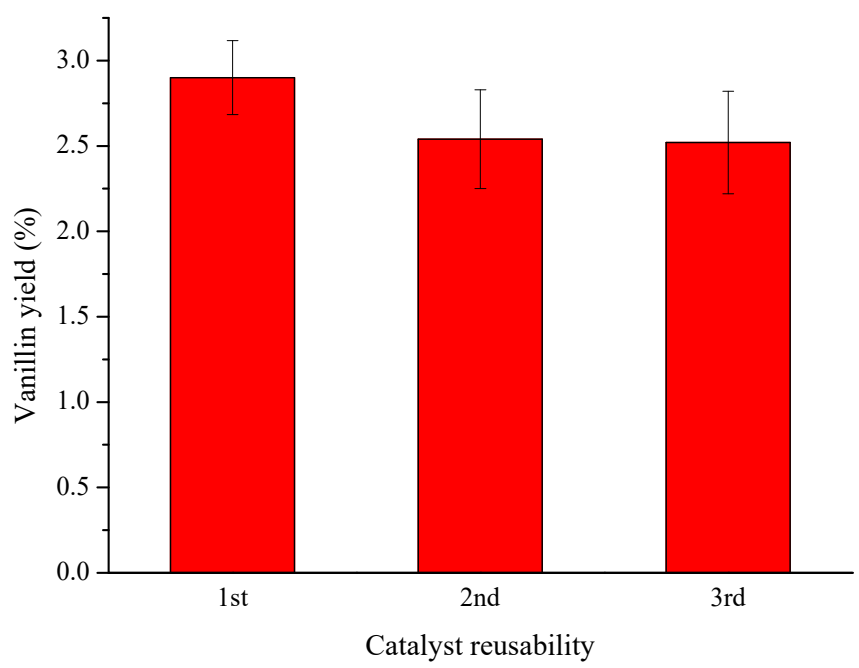

Figure 13. Reaction condition: $2 \mathrm{~g}$ of dried kenaf stalks, $20 \mathrm{~mL}$ of $0.01 \mathrm{~N} \mathrm{NaOH}$ solution, $15 \mathrm{wt}$ \% of catalyst, $1 \mathrm{~mL}$ of $\mathrm{H}_{2} \mathrm{O}_{2}$ at $20 \mathrm{~min}$ for $170{ }^{\circ} \mathrm{C}$.

\section{Materials and Methods}

\subsection{Catalyst Preparation}

$\mathrm{MgO}$ was synthesized using sol-gel and hydrothermal methods. First, $1 \mathrm{M}$ magnesium nitrate solution was prepared using magnesium nitrate hexahydrate $\left(\mathrm{Mg}\left(\mathrm{NO}_{3}\right)_{2} \cdot 6 \mathrm{H}_{2} \mathrm{O}\right)$ salts in the sol-gel method. Then, $1 \mathrm{M}$ sodium hydroxide $(\mathrm{NaOH})$ was added dropwise to the magnesium nitrate solution under vigorous stirring to adjust the $\mathrm{pH}$ to $\mathrm{pH} 12$. The mixture was stirred until a white solution was formed. Then, the white solution was dried at $120{ }^{\circ} \mathrm{C}$ for $12 \mathrm{~h}$ followed by calcination at $500{ }^{\circ} \mathrm{C}$ for $5 \mathrm{~h}$. The sample is denoted as $\mathrm{MgO}-$ $\mathrm{SG}$. For the synthesis of $\mathrm{MgO}$ under the hydrothermal method, the same procedure was repeated until the formation of a white solution. The white solution was then transferred to a Teflon-lined stainless steel hydrothermal vessel and left for crystallization at $120{ }^{\circ} \mathrm{C}$ for $18-48 \mathrm{~h}$, followed by drying at $120^{\circ} \mathrm{C}$ for $5 \mathrm{~h}$ and calcination at $500^{\circ} \mathrm{C}$ for $5 \mathrm{~h}$. The catalysts were denoted as $\mathrm{MgO}-18, \mathrm{MgO}-36$ and $\mathrm{MgO}-48$ for 18,36 and $48 \mathrm{~h}$ crystallization time. The calcined $\mathrm{MgO}$ was impregnated with 30 wt.\% of $\mathrm{Ce}$ using $\mathrm{Ce}\left(\mathrm{NO}_{3}\right)_{3} \cdot 6 \mathrm{H}_{2} \mathrm{O}$ via incipient wetness impregnation method. Typically, the required amount of metal salt was dissolved in a sufficient amount of distilled water before $\mathrm{MgO}$ was added to the solution and stirred for $3 \mathrm{~h}$ at room temperature. The slurry was then dried at $120^{\circ} \mathrm{C}$ for $12 \mathrm{~h}$ and calcined at $500{ }^{\circ} \mathrm{C}$ for $5 \mathrm{~h}$.

\subsection{Catalyst Characterization}

The crystallinity of the MgO-supported Ce catalysts was determined using Bruker $X$-ray diffraction (XRD) model $X^{\prime}$ Pert $^{3}$ Powder and Empyrean (PANanalytical, Billerica, MA, USA). The catalysts were recorded on an $X$-ray Diffractometer system between $2 \theta$ value of $20-80^{\circ}$ with $227 \mathrm{~s} /$ step exposure time and $0.105^{\circ} /$ step step size. Surface area and pore size of catalysts were analyzed using Brunauer-Emmett-Teller (BET) (Micromeritics ASAP 2020, Norcross, GA, USA). The catalysts were degassed at $20{ }^{\circ} \mathrm{C}$ for $24 \mathrm{~h}$, prior to $\mathrm{N}_{2}$ adsorption measurement at $-77^{\circ} \mathrm{C}$. The crystallite size of synthesized $\mathrm{MgO}$ particles was determined according to Scherrer's equation: $D=k \lambda / \beta \cos \theta$. Crystallite size were analyzed using HighScore Plus software (version 3.0), Malvern, UK with X-ray wavelength of $\mathrm{CuK} \alpha$ radiation at $\lambda=1.54 \mathrm{~A}^{\circ}$, where $\theta$ is Bragg angle. $\beta$ is the full width at half maximum in radians was taken corresponding to the $2 \theta$ value at plane (100) and (200). The unknown shape factor, $\mathrm{k}$, was assumed as 0.89 , the reflecting peak at $2 \theta$ was chosen for the entire sample. 


\subsection{Lignin Extraction and Characterization}

Dried kenaf stalks were broken into $10 \mathrm{~cm}$ lengths before being grinded into small pieces using a grinder. The extractive compounds such as protein, waxes, resin, fatty acids and lipid were removed from the dried kenaf stalks using a mixture of ethanol and water with (2:1) ratio via Soxhlet extraction for $8 \mathrm{~h}$. Extracted sample was dried in the oven for $24 \mathrm{~h}$ at $60{ }^{\circ} \mathrm{C}$. The dried residue was then soaked in an $\mathrm{NaOH}$ solution for 5 min with a sample to the solvent ratio $(6: 100 \mathrm{~g} / \mathrm{mL})$. The mixture was stirred and placed into a hydrothermal pressure vessel prior for the cooking process at $121^{\circ} \mathrm{C}$ for $2 \mathrm{~h}$ to break the bonds between lignin and hemicellulose. Heated mixture left to cool at room temperature before the separation of solid residue through filtration. The dark brown sample fluid (black liquor) was kept overnight at $4{ }^{\circ} \mathrm{C}$ (refrigerator). Black liquor was acidified by $\mathrm{H}_{3} \mathrm{PO}_{4}$ $(20 \%)$ at $\mathrm{pH}$ 2. Lignin precipitates into semi-solid form at around $\mathrm{pH} 14$. The precipitated lignin was then vacuum filtrated using a $0.45 \mu \mathrm{m}$ pore filter and washed using distilled water and $20 \% \mathrm{H}_{3} \mathrm{PO}_{4}$. The isolated was dried in an oven at $55^{\circ} \mathrm{C}$ for $48 \mathrm{~h}$ [43]. The sample was characterized using FTIR (Perkin Elmer Frontier 01, Cheshire, UK) between 500 and $4000 \mathrm{~cm}^{-1}$ for 50 scans with a resolution of $4 \mathrm{~cm}^{-1}$.

\subsection{Catalytic Oxidation of Raw Kenaf}

The performance of the catalyst was tested for the direct oxidation of kenaf stalks and extracted lignin to vanillin under microwave irradiation. Two grams of dried kenaf stalks and $1.06 \mathrm{~g}$ of dried lignin were soaked in $20 \mathrm{~mL}$ of $0.01 \mathrm{~N} \mathrm{NaOH}$ solution in a screw-cap test tube for $24 \mathrm{~h}$ before it was transferred to a Teflon tube. Then, $5 \mathrm{wt} . \%-15 \mathrm{wt} . \%$ of catalyst and $1 \mathrm{~mL}$ of $\mathrm{H}_{2} \mathrm{O}_{2}$ were added to the mixture and the $\mathrm{pH}$ was adjusted to $\mathrm{pH} 11.5$ and stirred at $600 \mathrm{rpm}$ for $10 \mathrm{~s}$ at room temperature using a magnetic stirrer before the mixture was heated in the $300 \mathrm{~W}$ of microwave heating (Milestone Srl, Milan, Italy, MicroSYNTH MA143) at $160-200{ }^{\circ} \mathrm{C}$ for $10-30 \mathrm{~min}$. Then, the mixture was cooled to room temperature and filtered through filter paper to remove the insoluble materials. The residue was washed with $20 \mathrm{~mL}$ of $0.01 \mathrm{~N} \mathrm{NaOH}$ solution twice. The same procedure was performed by changing the heterogeneous catalyst to a homogeneous sodium hydroxide catalyst to study vanillin production for direct oxidation from Kenaf stalks and extracted lignin. According to the obtained result, $15 \mathrm{wt} . \%$ was chosen as optimized catalyst loading for further study using $2 \mathrm{~N}$ of sodium hydroxide catalyst. The filtrate was transferred to a glass test tube with a cap. At the same time, the catalyst residue was washed several times with ethanol to further investigate catalyst reusability under optimized reaction conditions, followed by a drying process under an oven at $100{ }^{\circ} \mathrm{C}$ for $2 \mathrm{~h}$. Concentrated hydrochloric acid $(37 \%)$ was then added to the filtrate at a 1:2 ratio. The mixture was then agitated using a vortex agitator at $5000 \mathrm{rpm}$ for $15 \mathrm{~s}$, followed by centrifugation for $15 \mathrm{~min}$ at $1000 \mathrm{rpm}$. Next, ethyl acetate was added to the supernatant at a 1:1 ratio. The low molecular weight compounds were extracted into the organic phase, including vanillin. The mixture was agitated for $60 \mathrm{~s}$ at $5000 \mathrm{rpm}$ followed by centrifugation at $1000 \mathrm{rpm}$ for $5 \mathrm{~min}$, after which the mixture separated into two phases. The upper phase was transferred to a vial. Excess solvent was removed using a rotary evaporator at $50{ }^{\circ} \mathrm{C}$ and 400 mbar [12].

The brownish solution containing vanillin was analyzed using Agilent High Performance Liquid Chromatography (HPLC) with a UV-VIS detector at a wavelength of $280 \mathrm{~nm}$. The HPLC (Agilent 1200 series, Santa Clara, CA, USA) was equipped with Hypersil C18 column, Santa Clara, CA, USA (particle size of $5 \mu \mathrm{m}, 150 \times 4.6 \mathrm{~mm}$ inside diameter). The column temperature was set at $35^{\circ} \mathrm{C}$ and injection volume of $20 \mu \mathrm{L}$ with a mixture of acetonitrile: water $(1: 8 \mathrm{v} / \mathrm{v})$ containing $1 \%$ acetic acid used as the mobile phase at a flow rate of $2 \mathrm{~mL} \mathrm{~min}^{-1}$. Vanillin (Sigma-Aldrich, purity 99.7\%, Darmstadt, Germany) was used as standard [61]. 


\section{Conclusions}

Vanillin was successfully produced from direct oxidation of kenaf stalks and lignin extract from kenaf stalks under microwave heating using $\mathrm{H}_{2} \mathrm{O}_{2}$ as an oxidizing agent in the presence of $\mathrm{MgO}$-supported Ce catalysts at $\mathrm{pH} 11.5$. The vanillin yield of $3.70 \%$ was achieved from extracted lignin using 30Ce/MgO-48 catalyst at $170{ }^{\circ} \mathrm{C}$ for 20 min with catalyst loading of $15 \%$, while direct oxidation from kenaf stalks $2.90 \%$. On the other hand, the highest vanillin was obtained when $\mathrm{NaOH}$ was used as a homogeneous catalyst with $7.80 \%$ and $4.45 \%$ for oxidations of extracted lignin and direct biomass, respectively. The heterogeneous $30 \mathrm{Ce} / \mathrm{MgO}-48$ catalyst is chemically stable and can be repeated use for 3 times.

Supplementary Materials: The following are available online at https:/ /www.mdpi.com/article/ 10.3390/catal11121449/s1, Figure S1. X-ray diffraction patterns of MgO. (a) MgO-18; (b) MgO-36; (c) MgO-48; (d) MgO-SG, Figure S2. X-ray diffraction patterns of 30Ce/MgO. (a) 30Ce/MgO-18; (b) 30Ce/MgO-36; (c) 30Ce/MgO-48; (d) 30Ce/MgO-SG, Figure S3. Gas-chromatogram of degradation wood product.

Author Contributions: Conceptualization, A.R.; methodology, N.A.S.I.K.A.; software, A.R.; validation, A.R. and L.J.W.; formal analysis, N.A.S.I.K.A.; investigation, N.A.S.I.K.A.; resources, A.R. and L.J.W.; data curation, N.A.S.I.K.A.; writing—original draft preparation, N.A.S.I.K.A.; writing-review and editing, A.R.; visualization, A.R. and L.J.W.; supervision, A.R. and L.J.W.; project administration, A.R.; funding acquisition, A.R. and L.J.W.; All authors have read and agreed to the published version of the manuscript.

Funding: This research was funded by Malaysian Ministry of Higher Education under Fundamental Research Grant Scheme (FRGS/1/2020/STG04/UTP/02/2, cost center 015LC0-145) and MURATA SCIENCE FOUNDATION, grant no. 015ME0-026.

Data Availability Statement: Data is contained within the article or Supplementary Material.

Acknowledgments: The authors would like to thank Yayasan Universiti Teknologi PETRONAS for the research grants awarded to conduct the research and Universiti Teknologi PETRONAS for awarding Graduate Research Assistantship to Ms Nur Akila Syakida Idayu Khairul Anuar.

Conflicts of Interest: The authors declare no conflict of interest.

\section{References}

1. Maxence, F.; Bernard, B.; Sylvain, C. Vanillin production from lignin and its use as a renewable chemical. ACS Sustain. Chem. Eng. 2016, 4, 35-46.

2. Akriti, A.; Nirmala, K.; Soumitra, B. Derivatives and applications of lignin-An insight. Scitech J. 2014, 1, 30-36.

3. Nicholas, J.W.; Melinda, J.M.; Arjan, N. Vanillin. Phytochemistry 2003, 63, 505-515.

4. Pesach, L.; Matthew, V.D.; Alex, V.D. Pollination of vanilla and evolution in the Orchidaceae. Lindleyana 2006, 75, 926-929.

5. Pinto, P.; Da Silva, E.A.B.; Rodrigues, A.E. Lignin as source of fine chemicals: Vanillin and syringaldehyde. Methods Mol. Biol. 2012, 381-420.

6. Alireza, S.; Sepideh, M.R.; Ali, G. Oxidative production of vanillin from industrial lignin using oxygen and nitrobenzene: A comparative study. Int. J. Farming Appl. Sci. 2013, 2, 1165-1171.

7. Donostia, S.S. Lignin extraction, purification \& depolymerization study. Scitech J. 2012, 1, 30-36.

8. Zakzeski, J.; Bruijnincx, P.C.A.; Jongerius, A.L.; Weckhuysen, B.M. The catalytic valorization of lignin for the production of renewable chemicals. Chem. Rev. 2010, 110, 3552-3599. [CrossRef] [PubMed]

9. Sales, F.G.; Maranhão, L.C.; Filho, N.M.L.; Abreu, C.A. Experimental evaluation and continuous catalytic process for fine aldehyde production from lignin. Chem. Eng. Sci. 2007, 62, 5386-5391. [CrossRef]

10. Araújo, J.; Grande, C.; Rodrigues, A.E. Vanillin production from lignin oxidation in a batch reactor. Chem. Eng. Res. Des. 2010, 88, 1024-1032. [CrossRef]

11. Valery, E.T.; Konstantin, L.K.; Ekaterina, A.S.; Nikolay, T.; Yulia, V.C.; Olga, V.B.; Boris, N.K.; Laurent, D. Processing pine wood into vanillin and glucose by sequential catalytic oxidation and enzymatic hydrolysis. J. Wood Chem. Technol. 2016, 37, 43-51.

12. Chen, Q.; Masakazu, K.; Keiichiro, K.; Kanade, T.; Suguru, O.; Takashi, W. direct production of vanillin from wood particles by copper oxide-peroxide reaction production of vanillin from wood particles by copper oxide-peroxide reaction. ACS Sustain. Chem. Eng. 2017, 5, 11551-11557.

13. Chaudhary, R.; Dhepe, P.L. Solid base catalyzed depolymerization of lignin into low molecular weight products. Green Chem. 2017, 19, 778-788. [CrossRef] 
14. Long, J.; Zhang, Q.; Wang, T.; Zhang, X.; Xu, Y.; Ma, L. An Efficient and Economical Process for Lignin Depolymerization in Biomass-derived Solvent Tetrahydrofuran. Bioresour. Technol. 2014, 154, 10-17. [CrossRef]

15. Biswas, B.; Kumar, A.; Krishna, B.B.; Bhaskar, T. Effects of solid base catalysts on depolymerization of alkali lignin for the production of phenolic monomer compounds. Renew. Energy 2021, 175, 270-280. [CrossRef]

16. Ververis, C.; Georghiou, K.; Christodoulakis, N.; Santas, P.; Santas, R. Fiber Dimensions, Lignin and Cellulose Content of Various Plant Materials and Their Suitability for Paper Production. Ind. Crops Prod. 2004, 19, 245-254. [CrossRef]

17. Badr, M.M.; Mobasherpoura, I.; Marzban, E.R.; Mortazavic, G. Synthesis of cubic MgO nanostructure by an easy hydrothermalcalcinations method. J. Ceram. Process. Res. 2014, 15, 88-92.

18. Wahab, R.; Ansari, S.; Dar, M.; Kim, Y.S.; Shin, H.S. Synthesis of magnesium oxide nanoparticles by sol-gel process. Mater. Sci. Forum 2007, 558-559, 983-986. [CrossRef]

19. Bing, W.; Xingaoyuan, X.; Ren, H.; Zhi, Y.H. Preparation of MgO nanocrystals and catalytic mechanism on phenol ozonation. RSC Adv. 2017, 7, 43464-43473.

20. Li, X.; Xiao, W.; He, G.; Zheng, W.; Yu, N.; Tan, M. Pore size and surface area control of MgO nanostructures using a surfac-tanttemplated hydrothermal process: High adsorption capability to azo dyes. Colloids Surfaces A Physicochem. Eng. Asp. 2012, 408, 79-86. [CrossRef]

21. Widiyandari, H.; Sukmawati, A.N.; Sutanto, S.; Yudha, C.; Purwanto, A. Synthesis of $\operatorname{LiNi}_{0.8} \mathrm{Mn}_{0.1} \mathrm{Co}_{0.1} \mathrm{O}_{2}$ cathode material by Hydrothermal Method for High Energy Density Lithium Ion Batery. In Proceedings of the 9th International Conference on Physics and Its Applications: Journal of Physics, Surakarta, Indonesia, 14 August 2019.

22. Wang, J.A.; Novaro, O.; Bokhimi, X.; López, T.; Gómez, R.; Navarrete, J.; Llanos, M.E.; López-Salinas, E. Structural defects and acidic and basic sites in Sol-Gel MgO. J. Phys. Chem. B 1997, 101, 7448-7451. [CrossRef]

23. Ahmed, S. Development of Modified Si-MCM-41 and Studies on Its Behaviour for $\mathrm{CO}_{2}$ Adsorption. Ph.D. Thesis, Universiti Teknologi PETRONAS, Seri Iskandar, Malaysia, 2014.

24. Li, Z.P.; Wan, Y.Y.; Ji, F.W.; Jun, C.; Chuan, G.F.; Qian, F.Z. Low temperature synthesis of magnesium oxide and spinel powders by a Sol-gel Process. Mater. Res. 2010, 13, 339-343.

25. Krishnakanth, R.; Jayakumar, G.; Irudayaraj, A.A.; Raj, A.D. Structural and magnetic properties of $\mathrm{NiO}$ and Fe-doped $\mathrm{NiO}$ nanoparticles synthesized by chemical co-precipitation method. Mater. Today Proc. 2016, 3, 1370-1377. [CrossRef]

26. Setoudeh, N.; Zamani, C.; Sajjadnejad, M. Mechanochemical synthesis of nanostructured $\mathrm{Mg}_{\mathrm{X}} \mathrm{Ni}_{1-\mathrm{X}} \mathrm{O}$ compound by Mg-NiO mixture. Mater. Sci. 2017, 50, 51-59.

27. Bindu, P.; Thomas, S. Estimation of lattice strain in ZnO nanoparticles: X-Ray peak profile analysis. J. Theory Appl. Phys. 2014, 8, 123-134. [CrossRef]

28. Soo-Min, P.; Yoon-Chae, N.; Chunghee, N. Effects of hydrothermal treatment duration on morphology of $\mathrm{WO}_{3}$ nanostructures. J. Nanosci. Nanotechnol. 2017, 17, 7719-7722.

29. Chary, K.V.; Naresh, D.; Vishwanathan, V.; Sadakane, M.; Ueda, W. Vapour phase hydrogenation of phenol over Pd/C catalysts: A relationship between dispersion, metal area and hydrogenation activity. Catal. Commun. 2007, 8, 471-477. [CrossRef]

30. Roy, M.; Ghosh, S.; Naskar, M.K. Synthesis of morphology controllable porous $\mathrm{Co}_{3} \mathrm{O}_{4}$ nanostructures with tunable textural properties and their catalytic application. Dalton Trans. 2014, 43, 10248-10257. [CrossRef]

31. Matthias, T.; Katsumi, K.; Alexander, V.N.; James, P.O.; Francisco Rodriguez, E.R.; Jean, R.; Kenneth, S.W.S. Physisorption of gases, with special reference to the evaluation of surface area and pore size distribution (IUPAC Technical Report). Pure Appl. Chem. 2015, 87, 1051-1069.

32. Zhang, H.; Hu, J.; Xie, J.; Wang, S.; Cao, Y. A solid-state chemical method for synthesizing MgO nanoparticles with superior adsorption properties. RSC Adv. 2019, 9, 2011-2017. [CrossRef]

33. Chowdhury, I.H.; Bose, P.; Mandal, S.; Naskar, M.K. Effect of anion type on the synthesis of mesoporous nanostructured MgO, and its excellent adsorption capacity for the removal of toxic heavy metal ions from water. RSC Adv. 2016, 6, 6038-6047. [CrossRef]

34. Sui, C.; Xing, L.; Cai, X.; Wang, Y.; Zhou, Q.; Li, M. Co-supported CeO2Nanoparticles for CO catalytic oxidation: Effects of different synthesis methods on catalytic performance. Catalysts 2020, 10, 243. [CrossRef]

35. Mohamad Aini, N.A.; Othman, N.; Hussin, M.H.; Sahakaro, K.; Hayeemasae, N. Effect of extraction methods on the mo-lecular structure and thermal stability of kenaf (Hibiscus cannabinus core) biomass as an alternative bio-filler for rubber composites. Int. J. Biol. Macromol. 2020, 154, 1255-1264. [CrossRef] [PubMed]

36. Yang, S.; Wei, J.; Yuanming, Z.; He, W.; Fangwei, Z.; Kai, Y.; Guangting, H. A novel process of nanocellulose extraction from Kenaf Bast. Mater. Res. Express 2018, 5.

37. Yuting, Z.; Yuhe, L.; Wei, L.; Jing, L.; Xiangbo, S.; Lungang, C.; Chenguang, W.; Bert, F.S.; Longlong, M. complementing vanillin and cellulose production by oxidation of lignocellulose with stirring control. ACS Sustain. Chem. Eng. 2020, 8, 2361-2374.

38. Khalil, H.P.A.; Ismail, H.; Rozman, H.D.; Ahmad, M.N. The Effect of acetylation on interfacial shear strength between plant fiber and various matrices. Eur. Polym. J. 2001, 37, 1037-1045. [CrossRef]

39. Rodrigues, J.; Faix, O.; Pereira, H. Determination of lignin content of Eucalyptus globulus wood using FTIR spectroscopy. Holzforsch 1998, 52, 46-50. [CrossRef]

40. Hassan, N.S.; Badri, K.H. Lignin recovery from alkaline hydrolysis and glycerolysis of oil palm fiber. In Proceedings of the 2014 Universiti Kebangsaan Malaysia, Faculty of Science and Technology 2014 Postgraduate Colloquium, Selangor, Malaysia, 9-11 April 2014. 
41. Zhao, J.; Xiuwen, W.; Hu, J.; Liu, Q.; Shen, D.; Xiao, R. Thermal degradation of softwood lignin and hardwood lignin by TG-FTIR and Py-GC/MS. Polym. Degrad. Stab. 2014, 108, 133-138. [CrossRef]

42. Mohd Warid, M.N.; Ariffin, H.; Hassan, M.A.; Shirai, Y. Optimization of Superheated Steam Treatment to Improve Surface Modification of Oil Palm Biomass Fiber. BioResources 2016, 11, 5780-5796. [CrossRef]

43. Haridass, K. Synthesis of Renewable Vanillin from Pineapple Leaves Lignin. In Final Year Project Dissertation, Degree; Universiti Teknologi PETRONAS: Seri Iskandar, Malaysia, 2018.

44. Das, L.; Xu, S.; Shi, J. Catalytic oxidation and depolymerization of lignin in aqueous ionic liquid. Front. Energy Res. 2017, 5, 5. [CrossRef]

45. Nolan, M.; Fearon, J.E.; Watson, G.W. Oxygen vacancy formation and migration in ceria. Solid State Ion. 2006, 177, 3069-3074. [CrossRef]

46. Keating, P.R.; Scanlon, D.O.; Watson, G.W. The nature of oxygen states on the surfaces of $\mathrm{CeO}_{2}$ and La-doped CeO . Chem. Phys. Lett. 2014, 608, 239-243. [CrossRef]

47. Gu, T.; Liu, Y.; Weng, X.; Wang, H.; Wu, Z. The enhanced performance of ceria with surface sulfation for selective catalytic reduction of $\mathrm{NO}$ by $\mathrm{NH}_{3}$. Catal. Commun. 2010, 12, 310-313. [CrossRef]

48. Tarabanko, V.E.; Tarabanko, N. Catalytic oxidation of lignins into the aromatic aldehydes: General process trends and development prospects. Int. J. Mol. Sci. 2017, 18, 2421. [CrossRef] [PubMed]

49. Tarabanko, V.E.; Gulbis, G.R.; Ivanchenko, N.M.; Kuznetsov, B.N.; Kudryashev, A.V. Study of wood and lignosulfonates processing into fine products. Chem. Sustain. Dev. 1996, 4, 405-417.

50. Amarasekara, A. Acidic ionic liquids. Chem. Rev. 2016, 116, 6133-6183. [CrossRef]

51. Prado, R.; Erdocia, X.; de Gregorio, G.F.; Labidi, J.; Welton, T. Willow lignin oxidation and depolymerization under low cost ionic liquid. ACS Sustain. Chem. Eng. 2016, 4, 5277-5288. [CrossRef]

52. Lu, J.; Wang, M.; Zhang, X.; Heyden, A.; Wang, F. $\beta-\mathrm{O}-4$ bond cleavage mechanism for lignin model compounds over Pd catalysts identified by combination of first-principles calculations and experiments. ACS Catal. 2016, 6, 5589-5598. [CrossRef]

53. Jiang, L.; Guo, H.; Li, C.; Zhou, P.; Zhang, Z. Selective cleavage of lignin and lignin model compounds without external hydrogen, catalyzed by heterogeneous nickel catalysts. Chem. Sci. 2019, 10, 4458-4468. [CrossRef] [PubMed]

54. Da Costa Lopes, A.M.; Gomes, J.R.B.; Coutinho, J.A.P.; Silvestre, A.J.D. Novel insights into biomass delignification with acidic deep eutectic solvents: A mechanistic study of $\beta$-O-4 ether bond cleavage and the role of the halide counterion in the catalytic performance. Green Chem. 2020, 22, 2474-2487. [CrossRef]

55. Deng, W.; Zhang, H.; Wu, X.; Li, R.; Zhang, Q.; Wang, Y. Oxidative conversion of lignin and lignin model compounds catalyzed by CeO2-supported Pd nanoparticles. Green Chem. 2015, 17, 5009-5018. [CrossRef]

56. Ma, Y.; Du, Z.; Liu, J.; Xia, F.; Xu, J. Selective oxidative C-C bond cleavage of a lignin model compound in the presence of acetic acid with a vanadium catalyst. Green Chem. 2015, 17, 4968-4973. [CrossRef]

57. Liu, H.; Li, H.; Lu, J.; Zeng, S.; Wang, M.; Luo, N.; Xu, S.; Wang, F. Photocatalytic cleavage of C-C Bond in lignin models under visible light on mesoporous graphitic carbon nitride through $\pi-\pi$ stacking interaction. ACS Catal. 2018, 8, 4761-4771. [CrossRef]

58. Fan, H.; Yang, Y.; Song, J.; Ding, G.; Wu, C.; Yang, G.; Han, B. One-pot sequential oxidation and aldol-condensation reactions of veratryl alcohol catalyzed by the Ru@ZIF-8 + CuO/basic ionic liquid system. Green Chem. 2014, 16, 600-604. [CrossRef]

59. Xu, C.; Arancon, R.A.D.; Labidi, J.; Luque, R. Lignin depolymerisation strategies: Towards valuable chemicals and fuels. Chem. Soc. Rev. 2014, 43, 7485-7500. [CrossRef] [PubMed]

60. Shilpy, M.; Ehsan, M.A.; Ali, T.H.; Abd Hamid, S.B.; Ali, M.E. Performance of Cobalt Titanate Towards $\mathrm{H}_{2} \mathrm{O}_{2} \mathrm{Based} \mathrm{Catalytic}$ Oxidation of Lignin Model Compound. RSC Adv. 2015, 5, 9644-79653. [CrossRef]

61. Saberi, F.; Rodriguez-Padrón, D.; Garcia, A.; Shaterian, H.; Luque, R. Unprecedented Proline-Based Heterogeneous Organocatalyst for Selective Production of Vanillin. Catalysts 2018, 8, 167. [CrossRef] 